\title{
Mobile and Executive Computing- A Review
}

\author{
Shivangi Kaushal \\ ASET(CSE), Amity University Haryana \\ Email:sbhardwaj@ggn.amity.edu
}

\begin{abstract}
Fears regarding financial conditionsand increasing contention create weights tochop prices, that expect organizations to seem for artistic approaches to travel into Associate in Nursing association with consumers. This investigation centers around transportable trade and its prosperity factors, associated with plans of action and versatile advances, thus on accomplish the most effective work between business, clients, and innovation. To accomplish these goals, the current examination surveys writing known with plans of action, $\mathrm{m}$-trade and its prosperity factors, and figures a network that facilitate in coordinative between plans of action and $\mathrm{m}$ commerce accomplishment factors.
\end{abstract}

Index Terms-Mobile computing; m-Commerce; Technology.

\section{INTRODUCTION}

In developing markets where cell phones are the minority, you require an alternate procedure. Everybody and everything are going portable, so it's no big surprise that online business is now offering approach to $\mathrm{m}$-trade and all the $\mathrm{m}$-business advances that are venturing into our lives alongside it. The progressions are major, as versatile business is currently changing the biggest and most lucrative enterprises that we depend on. The advances it utilizes are commonplace: AR, VR, reference points, push notices, and that's just the beginning. By and by, they bring forth numerous interesting m-trade drifts that may turn these ventures on their head - gradually and positively. The different industries that are into the mobile commerce are retail industry, finance and banking industry, sports industry and many more.

Versatile business or m-trade is characterized as any immediate or aberrant exchange with potential money related esteem directed by means of remote media transmission systems. Utilizing mobile administrations, clients can send/get messages, download music/designs/liveliness, look for merchandise and enterprises, play intuitive internet recreations, exchange stocks, book tickets, find companions, direct monetary and managing an account exchanges et cetera (Frolick and Chen, 2004). One of the fundamental advantages of utilizing m-trade administrations is the capacity to complete assignments anyplace, whenever.

\section{TECHNOLOGIES/ PLATFORMS}

The four different conventions for mobile commerce are discussed below:

\subsection{SMS}

SMS, is the most recognized of these innovations and the generally broadly utilized. SMS messages can transmit one-way, push, for example, alarms, news, offers and other data from content suppliers to followers.

What's more, SMS can suggest parallel information, so it can be the isolated conveyance system for downloads. SMS additionally underpins two-way intuitive informing; including permitting bank accountholders so that they can have a look at their present record adjusts by messaging to a telephone number. The primary focal points of SMS are its universality and convenience: it is accessible all over the place and is available to all endclients regardless of their remote bearer or cell phone write. The primary downside of SMS is absence of encryption. SMS administrations can't utilize Personal Identification Numbers (PINs) for confirmation, since duplicates of messages are put away in the unsecured Sent envelope (Andrew Mikesell). This confines SMS to administrations that don't require verification or that involve the PIN to be asked for, in another standard, for example, by an Interactive Voice Response (IVR) call to the supporter of demand the PIN. While Multimedia Messaging Service (MMS), or picture informing, is broadly utilized as a part of a few markets, it is for the most part not utilized as a part of versatile business administrations. MMS is costlier than SMS and controlling how it shows up on the gadget is troublesome. One special case is MMS for standardized identifications (Andrew Mikesell).

\subsection{USSD}

USSD is accessible just for outside administrations in a set figure of business sectors. Not at all like SMS, has USSD built up an ongoing association that takes into consideration genuine session-based interchanges. Consider it the portable adaptation of IVR frameworks that numerous organizations use for client service but without the voice. Like SMS, USSD can transmit push notices, answer inquiries from clients the accessible adjust in a prepaid versatile record also, top-up the adjust on prepaid portable records. Additionally, like SMS, USSD is open from for all intents and purposes any cell phone, and utilizing it is simple. A major favorable position of USSD is consolidation of secure secret word or portable PIN assurance, since sent messages are not put away on the gadget. USSD has disadvantages. Charging for administrations is troublesome in light of the fact that transporters don't have a worked in charging component. It isn't ensured to work when you wander. What's more, your telephone 
must be swung on to get messages (Andrew Mikesell). At the point when your telephone is off, out of range or in a no man's land, for example, inside a lift, you won't get the message and not at all like SMS, USSD gives no capacity to resend messages. Thus, USSD isn't a decent alternative for administrations, for example, extortion alarms.

\subsection{WAP/Mobile Web}

Since the dispatch of iPhone, most cell phones have upheld programs that help HTML. A WAP client experience can be near what you get with a fundamental portable application. The pervasive correspondence tradition used today for M-business is the Wireless Application Protocol (WAP). WAP is a determination that permits versatile clients to get email, synchronize schedules, and get to databases right away finished the Internet through handheld remote gadgets. WAP is intended to work with most remote systems and the present portable correspondence stages. WAP has increased wide acknowledgment due to its use of the current Internet innovation and simplicity of sending. It is good with the lion's share of handsets at present available. WAP, in any case, isn't without its issues. It has a tendency to be Or maybe moderate since it was not initially intended for broadband correspondence. Notwithstanding the absence of highspeed association, the dependability of the administrations to a great extent relies upon the area of the client. WAP can likewise be costly. WAP charges incrementally. Subsequently, longer association times mean higher cell phone charges (Xin, 2009).

\subsection{STK}

By the means of SIM Toolkit (STK), an application is manufactured by the engineers, which is put away on the Subscriber Identity Module (SIM) card and shows up in the best level menu of a component telephone. STK licenses these applications to request and get information from SIM, offer summons to the mobile phone, ask for commitment from the customer and talk with external applications. A few organizations use STK for compact dealing with a record and distinctive sorts of utilizations with direct interfaces and a low level of value. The essential preferred standpoint of STK is security as identity affirmation and encryption. From a security stance, giving endorsers a STK application resembles giving them a committed terminal. STK is perfect for money related or portable business arrangements where clients approach a system of trade out/money out operators. The test of STK is that it more often than not requires the bearer to issue another SIM card. Therefore, it is best to utilize STK in restricted circulation conditions By the means of SIM Toolkit (STK), an application is manufactured by the engineers, which is put away on the Subscriber Identity Module (SIM) card and shows up in the best level menu of a component telephone. STK licenses these applications to request and get information from SIM, offer summons to the mobile phone, ask for commitment from the customer and talk with external applications. A few organizations use STK for compact dealing with a record and distinctive sorts of utilizations with direct interfaces and a low level of value. The essential preferred standpoint of STK is security as identity affirmation and encryption. From a security stance, giving endorsers a STK application resembles giving them a committed terminal. STK is perfect for money related or portable business arrangements where clients approach a system of trade out/money out operators. The test of STK is that it more often than not requires the bearer to issue another SIM card. Therefore, it is best to utilize STK in restricted circulation conditions.

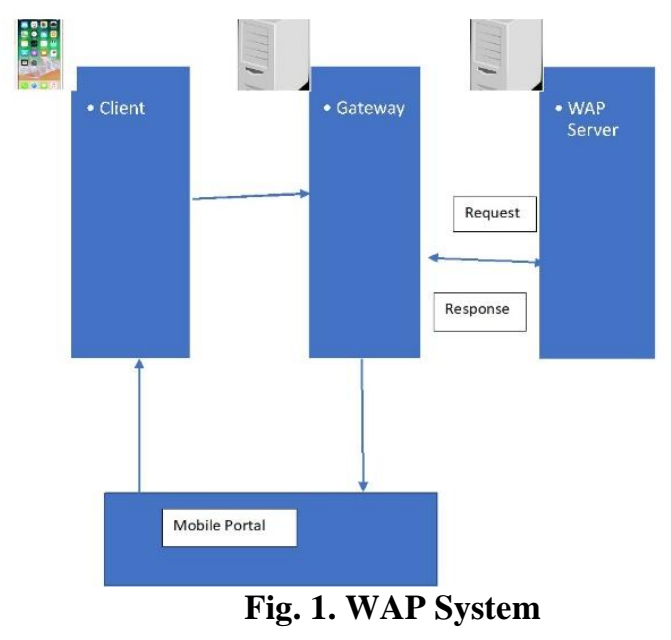

\section{SUCCESS FACTORS}

There are several success factors that are to be critically reviewed which are as follows:

1. Attitude towards the use of mobile services: The end-users' Perspective

2. Value-added-based acceptance model of mobile commerce

3. Keep reading more about mobile optimization

4. Leverage customer feedback (Feng, Hoegler and Stucky, 2006)

5. Perceived ease of use (Romi, 2012)

6. Perceived Trust (Saifullah Sadi and Noordin, 2011)

3.1 Cost Factors that affect the mobile business solutions:

1. Mobile application development cost- There are various components that decide your aggregate versatile application improvement cost, yet experienced portable designers can take proposed highlight records and give their customers a range that for the most part covers the enchantment number the customers are searching for. Some of the drivers are scalability, data encryption, storage of the data, and more.

2. Data Security Costs- Guaranteeing information security is fundamental to the congruity of the whole application advancement venture. Security ought to never be dealt with gently. So, if your application is prepared for the dispatch yet you haven't settled down the security concerns, don't continue further. Each conceivable advance ought to be taken to 


\section{International Journal of Research in Advent Technology, Vol.7, No.5, May 2019 E-ISSN: 2321-9637 \\ Available online at www.ijrat.org}

guarantee the security of client information, passwords and other data connected with the application use. At to start with, this may appear to be a tedious and costly errand, yet it is essential to capturing the significance of securing your portable application keeping in mind the end goal to proffer a smooth and alluring client encounter. On the off chance that you fizzle at executing satisfactory security registers with your application, you may confront a noteworthy security rupture, malware assault, viral disease or framework assaults, amending which will at last cost you significantly more than introducing a watchful security system in the very begin. In this manner, put carefully and adequately in a strong versatile application security so your application can effectively battle the dangers required for the incentive to data stored API works out of sight, free of the client, along these lines making intuitiveness between applications which is completely consistent and prudent. One of the best and exceedingly effective outside API benefits is Twilio. This paid administration allows its clients to profit by joining a pre-characterized API usefulness into their own particular programming stages. Utilizing the administration, your versatile application can make calls or send messages to some other cell phone effortlessly and viably.

3. Platforms and Devices used- The help and programming required for various screen resolutions and gadgets rapidly moves toward becoming asset serious, requiring a greater amount of engineers' opportunity which could lead to the cost of advancement to twofold or even triple. The quantity of stages and gadgets you have to create for may at last have the greatest effect on the cost of your versatile application.

4. Cost of external API- Programming interface works out of sight, free of the client, in this manner making intelligence between applications which is completely consistent and cautious. One of the best and exceedingly proficient outside API benefits is Twilio. This paid administration allows its clients to profit by fusing a pre-characterized API usefulness into their own product stages. Utilizing the administration, your versatile application can make calls or send messages to some other cell phone effortlessly and adequately.

\section{CONCLUSION}

Mobile trade offers another business chance to ventures and customers, yet before the opportunity move toward becoming as a real business, a few obstructions should be overcome. An arrangement of components can possibly emphatically influence the accomplishment of m-trade and ought to be taken into account by endeavors while embracing mobile commerce. In this assignment the different technologies or the platforms used for mobile commerce has been discussed. The factors that affect the overall use of more and more mobile commerce have also been discussed. Various cost factors that affect the implementation of business solutions have been taken into account so far for the mobile business solution.

\section{REFERENCES}

[1] Xin, "Technologies and Challenges of MCommerce," International Conference on Environmental SCience and Information Application Technology, pp. 518-521, 2009.

[2] N. Saifullah Sadi, "Factors Influencing the adoption of M-Commerce: An exploratory analysis," Proceedings of the International Conference on Industrial Engineering and Operations Management Kuala Lumpur, malaysia, pp. 492-499, 2011.

[3] H. S. Feng, "Exploring the Critical Success Factors for Mobile Commerce," Proceedings of the International Conference on Mobile Business, 2006.

[4] C. Frolick, "Assessing M-Commerce Opportunities," Information System Management, pp. 53-57, 2004.

[5] A. Mikesell, "4 main technologies underlying mobile commerce apps," [Online]. Available: ttps://www.mobilemarketer.com/ex/mobilemarketer /cms/opinion/columns/13201.html. [Accessed May 2018].

[6] V. a. Vetter, "A Framework for the Emerging Mobile Commerce Applications," Proceedings of the 34th Hawaii International Conference on System Sciences, IEEE Comp Society Press., 2001.

[7] Romi, "Mobile Commerce Success Factors for the Various Business Models," Proceedings 2nd Computer Science On-Line Conference, vol. 1, no. 6, pp. 156-163, 2012.

[8] L. a. Viehland, "Factors Influencing the Adoption of Mobile Learning," 19th Australasian Conference on Information Systems Adoption of Mobile Learning, 2008.

[9] P. a. Arvind, "Business solutions using mobile technologies: For action on various approval requests," International Mutli-Conference

on Automation, Computing, Communication, Control and Compressed Sensing, 2013.

[10] W. a. Wang, "What drives mobile commerce? An empirical evaluation of the revised technology acceptance model," Science Direct: Information and Management, pp. 719-729, 2004.

[11] N. a. Gunasekaran, "A review for mobile commerce research and applications," ScienceDirect: Decision Support system, pp. 3-15, 2005.

[12] Anwar, "NTT DoCoMo and m-commerce: a case study in market expansion and global strategy," Thunderbird International Business Review, p. $139-$ 164, 2002.

[13] B. a. Pavlou, "Evidence of the effect of trust building technology in electronic markets: price premiums and buyer behavior," MIQ Quarterly, p. 243-268, 2002.

[14] Constantinides, "The 4S Web-marketing mix model, electronic commerce research and applications," Elsevier Science, vol. 1, no. 1, pp. 57-76, 2002. 
International Journal of Research in Advent Technology, Vol.7, No.5, May 2019

E-ISSN: 2321-9637

Available online at www.ijrat.org

[15] Davis, "Perceived usefulness, perceived ease of use, and user acceptance of information technologies," MIS Quarterly, vol. 13, no. 3, pp. 319-340, 1989.

[16] Eastin, "Diffusion of e-commerce: an analysis of the adoption of four E-commerce activities," Telematics and Informatics, vol. 19, no. 3, p. 251-267, 2002. 